\title{
Analysis, Design and Control of a Transcutaneous Power Regulator for Artificial Heart
}

\author{
Qianhong Chen ${ }^{* * *}$, Siu Chung Wong ${ }^{\dagger}$, Chi K. Tse ${ }^{\dagger}$, and Xinbo Ruan* \\ ${ }^{*}$ College of Automation Engineering, Nanjing University of Aeronautics \& Astronautics, Nanjing 210016, China \\ **Also with Department of Electronic and Information Engineering, Hong Kong Polytechnic University, Hong Kong \\ while this work was performed \\ ${ }^{\dagger}$ Department of Electronic and Information Engineering, Hong Kong Polytechnic University, Hong Kong \\ (email: enscwong@polyu.edu.hk)
}

\begin{abstract}
Based on commonly used parameters for a generic transcutaneous transformer model, a remote power supply using resonant topology for artificial heart is analyzed and designed for easy controllability and high efficiency. Primary and secondary windings of the transcutaneous transformer are positioned outside and inside human body respectively for energy transfer. The two large leakage inductances and the mutual inductance of the transformer are varying parameters of the coupling-coefficient which varies with transformer alignment and gap due to external positioning. Varying resonant-frequency resonant-tank circuits are formed using the transformer inductors and external capacitors to obtain a load insensitive frequency for the voltage transfer function at given range of coupling coefficients and loads. Previous researches usually use frequency modulation which may require a wide control frequency range well above the load insensitive frequency. In this paper, fundamental frequency study of the input-to-output voltage transfer function is carried out. Using the proposed control method, the switching frequency can be locked at just above the load insensitive frequency at heavy load for best efficiency. Specifically, above resonant operation in driving the resonant circuits when varying the coupling-coefficient is maintained using a digital-phase-lock-loop (PLL) technique to achieve zerovoltage switching of a full-bridge switches configuration which is also programmed to provide pulse-width-modulation (PWM) in controlling the output voltage. A prototype transcutaneous power regulator is built and found to have good efficiency and regulation in responding to changing alignment or gap of the transcutaneous transformer, load and input voltage dynamically.
\end{abstract}

\section{INTRODUCTION}

Advances in technology allow artificial organs or monitoring devices to be implanted into human body for the extension and improvement of human lives. The implants must operate inside the body for a considerable period of time and communicate with the outside world wirelessly with medical data and commands. Among power sources by chemical, nuclear or bio-chemical methods, chemical rechargeable batteries are by far the safer and popular reusable power for the implant inside the human body. The rechargeable battery is recharged remotely through the human skin using inductive link, like the one used in rechargeable toothbrushes with separate wireless chargers.

Totally implantable systems minimize the risk of infection and improve patient's mobility. Reliable and safe methods in providing power for the implants are the key factors in achieving totally implantable systems. Inductive link technology is widely used for powering different kinds of implants

This work was supported by Hong Kong Research Grants Council under project CERG PolyU 5306/06E.
[1]-[23]. Pure air coil type transformer has been used and studied in [1], [2], [4], [5], [6], [8], [10], [13] and [23], within which [1], [2] and [8] use class E power converter, for low power applications and space saving. Discussion on the importance of battery power source can be found in [14]. For higher power applications, such as powering the artificial heart for a power level of 10-60 W, magnetic cores are used [3], [7], [9], [11], [12], [15]-[22]. To compensate for the large leakage inductances due to transcutaneous separation, resonant type converter of class D [9], [13], [17], [20], [21] is used. More detailed studies in using resonant converter for compensating the leakage inductances have been conducted by Cho et. al [17], [20], [21]. However, their studies uses a wide frequency range for frequency modulation in controlling the converter at a less than ideal output-to-input voltage transfer ratio of 0.45 [17] and have not fully demonstrate an effective control method for output voltage regulation dealing with changing transformer coupling coefficient, input voltage and load.

In this paper, we will present a PWM-PLL control method for transcutaneous power regulator using a generic transformer model whose coupling coefficient is changing with transformer alignment and gap. The transformer model and its equivalent parameters commonly used in transcutaneous transformer [9], [13], [17], [20], [21] is given in Section II. In Section III, resonant tank circuits using external capacitors and the inductances of the transcutaneous transformer are studied. Fundamental frequency analysis is preformed for the input-to-output voltage transfer function to obtain an operation frequency upon which the voltage transfer function is least sensitive to both load and transformer variations. Design and control of a transcutaneous power converter in regulating output voltage against changing coupling coefficient, load and input voltage is presented in Section IV. A prototype transcutaneous power regulator is built and its static and dynamic performances are evaluated in Section V. Finally, we conclude in Section VI.

\section{EXAMPLE LEAKAgE INDUCTANCES OF TRANSCUTANEOUS TRANSFORMER}

We use the transformer model in Fig. 1(a) to represent a transcutaneous transformer where all components are lossless. Using the power level and size of cores used in [9], [13], [17], [20], [21], we have built our own a transcutanous transformer using Planar Core E64/10/50 for an air gap length (skin depth) ranging from $10 \mathrm{~mm}$ to $20 \mathrm{~mm}$. The parameters 


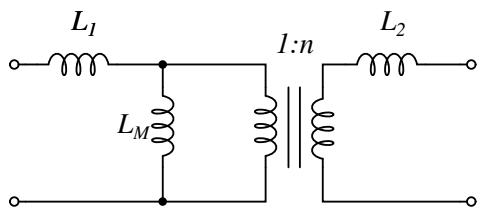

(a)

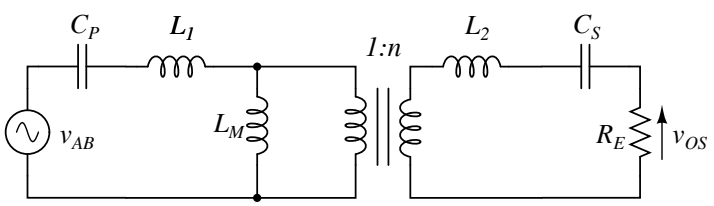

(b)

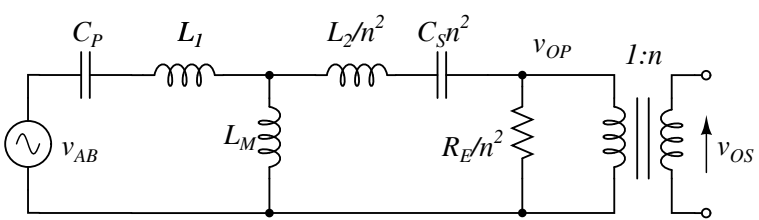

(c)

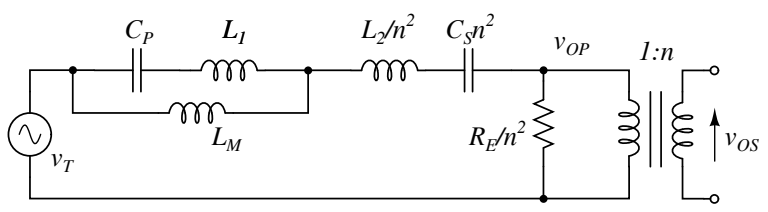

(d)

Fig. 1. Transformer model and compensation circuits.

TABLE I

Transcutaneous Transformer Parameters

\begin{tabular}{llllllll}
\hline Air gap & $\begin{array}{l}\text { Mis- } \\
\text { alignment } \\
(\mathrm{mm})\end{array}$ & $L_{P}$ & $L_{S}$ & $L_{1}$ & $L_{2}$ & $L_{M}$ & $k$ \\
$(\mathrm{~mm})$ & $(\mu \mathrm{H})$ & $(\mu \mathrm{H})$ & $(\mu \mathrm{H})$ & $(\mu \mathrm{H})$ & $(\mu \mathrm{H})$ & \\
\hline 20 & 10 & 42.60 & 38.13 & 30.32 & 28.30 & 12.27 & 0.273 \\
20 & 0 & 42.63 & 38.14 & 30.03 & 28.06 & 12.56 & 0.279 \\
10 & 0 & 49.41 & 43.53 & 21.85 & 21.46 & 27.56 & 0.532 \\
\hline
\end{tabular}

the example transformer emulated represent the trend of leakage inductances and mutual inductance of other transformer designs [3], [7], [9], [11], [12], [15]-[22]. Therefore, as our target is on the design and control of a power regulator for transcutaneous converter application, the parameters of the example transformer should be adequate. Some of the parameters measured for various coupling coefficients $k$ are shown in Table I, where

$$
\begin{array}{rcl}
L_{P}(k) & = & L_{1}(k)+L_{M}(k), \\
L_{S}(k) & = & L_{2}(k)+n^{2} L_{M}(k), \\
k=\frac{n L_{M}}{\sqrt{L_{P} L_{S}}}, &
\end{array}
$$

and the turn-ratio of the transformer is $n=0.895$. As indicated in Table I, all inductance values change with $k$, i.e. air gap or misalignment length. Normally, external capacitances $C_{P}$ and $C_{S}$ are added to form resonant tanks with the transformer inductances [17]. The frequency of resonant tanks is thus changed with changing $k$.

\section{Fundamental FReQUency AnAlysis of RESONANT TANK CIRCUITS USING TRANSCUTANEOUS TRANSFORMER MODEL}

We consider the fundamental frequency equivalent circuit in Fig. 1(b) where the transformer has been compensated using external capacitors $C_{P}$ and $C_{S}$ to transfer energy from the ac equivalent source $v_{A B}$ to the equivalent load $R_{E}$. The components in the secondary side of the ideal transformer are transformed to their equivalents in the primary side shown in Fig. 1(c) which is further transformed to its Thévenin's equivalent shown in Fig. 1(d) for the calculation of inputto-output voltage transfer function $\frac{v_{O S}}{v_{A B}}(\omega)$. We have from Fig. 1(c) and (d):

$$
\begin{aligned}
v_{T} & =v_{A B} \frac{j \omega L_{M}}{Z_{P}}, \\
Z_{T} & =-\frac{\omega L_{M}\left(\omega L_{1}-\frac{1}{\omega C_{P}}\right)}{Z_{P}}, \\
v_{O P} & =v_{T} \frac{R_{E} / n^{2}}{Z_{T}+Z_{S} / n^{2}+R_{E} / n^{2}-j \omega L_{M}} \\
& =v_{A B} \frac{\omega L_{M}}{Z_{P}} \frac{R_{E}}{n^{2} Z_{T}+Z_{S}+R_{E}-j n^{2} \omega L_{M}},
\end{aligned}
$$

where

$$
\begin{aligned}
& Z_{P}=j\left(\omega L_{P}-\frac{1}{\omega C_{P}}\right), \\
& Z_{S}=j\left(\omega L_{S}-\frac{1}{\omega C_{S}}\right) .
\end{aligned}
$$

The input-to-output voltage transfer function is determined from (4) as

$$
\begin{aligned}
G_{v}(\omega) & =\frac{v_{O S}}{v_{A B}}=\frac{n v_{O P}}{v_{A B}} \\
& =\frac{\omega n L_{M} R_{E}}{\left(Z_{S}+R_{E}\right) Z_{P}+n^{2} \omega L_{M}^{2}} \\
& =\frac{n}{\frac{Z_{P}}{\omega L_{M}}+\frac{\Delta}{\omega^{3} C_{S} C_{P} R_{E} L_{M}}}
\end{aligned}
$$

where

$$
\begin{aligned}
\Delta & =\omega^{4} C_{P} C_{S}\left(n^{2} L_{M}^{2}-L_{P} L_{S}\right)+\omega^{2}\left(L_{P} C_{P}+L_{S} C_{S}\right)-1 \\
& =\omega^{4} L_{P} C_{P} L_{S} C_{S}\left(k^{2}-1\right)+\omega^{2}\left(L_{P} C_{P}+L_{S} C_{S}\right)-1 .
\end{aligned}
$$

It can be readily seen in (7) that if $\Delta=0$, then $G_{v}$ is independent of $R_{E}$. Solving for roots of (8), we obtain

$$
\begin{aligned}
& \omega_{L}=\sqrt{\frac{\omega_{P}^{2}+\omega_{S}^{2}-\sqrt{\left(\omega_{P}^{2}+\omega_{S}^{2}\right)^{2}-4\left(1-k^{2}\right) \omega_{P}^{2} \omega_{S}^{2}}}{2\left(1-k^{2}\right)}}, \\
& \omega_{H}=\sqrt{\frac{\omega_{P}^{2}+\omega_{S}^{2}+\sqrt{\left(\omega_{P}^{2}+\omega_{S}^{2}\right)^{2}-4\left(1-k^{2}\right) \omega_{P}^{2} \omega_{S}^{2}}}{2\left(1-k^{2}\right)}},
\end{aligned}
$$

where

$$
\begin{gathered}
\omega_{P}=\frac{1}{\sqrt{L_{P} C_{P}}}, \\
\omega_{S}=\frac{1}{\sqrt{L_{S} C_{S}}} .
\end{gathered}
$$


TABLE II

Percentage Change of Inductance Ratio when Changing $k$

\begin{tabular}{llll}
\hline & $\frac{L_{S}}{L_{P}}$ & $\frac{L_{2}}{L_{1}}$ & $k$ \\
\hline & 0.895 & 0.933 & 0.273 \\
& 0.895 & 0.934 & 0.279 \\
& 0.881 & 0.982 & 0.532 \\
\hline Maximum change & $-1.56 \%$ & $+4.99 \%$ & \\
\hline
\end{tabular}

From Fig. 1(c), the input impedance $Z_{I}$ is given as

$$
Z_{I}=Z_{P}+\frac{\omega^{2} n^{2} L_{M}^{2}}{Z_{S}+R_{E}}
$$

which after some manipulations can be expresses as

$$
Z_{I}=\frac{Z_{P} R_{E}}{Z_{S}+R_{E}}+\frac{\Delta}{\omega^{2} C_{P} C_{S}\left(Z_{S}+R_{E}\right)} .
$$

\section{A. Leakage Inductance Compensation}

It has been shown [17] that when the two leakage inductances are compensated using external capacitances satisfying $L_{1} C_{P}=L_{2} C_{S}, 1 / \sqrt{L_{1} C_{P}}$ and $1 / \sqrt{\left(L_{S}+L_{M}\right) C_{P}}$ are two roots of $\Delta$ and $\left|G_{v}\right|=n$ in (7). However, the compensation technique can only be optimized at one particular $k$ at which the equality $L_{1} C_{P}=L_{2} C_{S}$ holds. When $k$ changes, $L_{1}$ and $L_{2}$ change as well, leaving $\left|G_{v}\right|$ deviating from $n$.

We propose here to use capacitances satisfying

$$
L_{P} C_{P}=L_{P} C_{S}
$$

as an additional method in compensating the leakage inductances. In doing so, using the approximations

$$
\frac{L_{M}}{L_{P}} \approx k \approx \frac{n^{2} L_{M}}{L_{S}},
$$

equations (9), (10) and (7) reduce to

$$
\begin{aligned}
\omega_{L} & =\frac{\omega_{P}}{\sqrt{1+k}} \approx \frac{1}{\left(L_{P}+L_{M}\right) C_{P}}, \\
\omega_{H} & =\frac{\omega_{P}}{\sqrt{1-k}} \approx \frac{1}{L_{1} C_{P}}, \\
G_{v}\left(\omega_{L}\right) & \approx n, \\
G_{v}\left(\omega_{H}\right) & \approx n .
\end{aligned}
$$

The required ratio of $\frac{C_{P}}{C_{S}}$, indicated on columns $\frac{L_{S}}{L_{P}}$ and $\frac{L_{2}}{L_{1}}$ in compensating the inductances are given in Table II, showing better accuracy of the proposed compensation for the particular transformer at $\omega_{H}$ and $\omega_{L}$ in achieving $\left|G_{v}\right| \approx n$.

For the subsequence analysis, the compensation method (15) and approximation (16) will be used. We define

$$
\begin{aligned}
\omega_{0} & =\omega_{P}=\omega_{S}, \\
\omega_{r} & =\frac{\omega}{\omega_{0}}, \\
Q & =\frac{\sqrt{\frac{L_{P}}{C_{P}}}}{R_{E}},
\end{aligned}
$$

then

$$
\begin{aligned}
Q_{S} & =n^{2} Q \\
\left|v_{C_{S}}\right| & =\left|\frac{n^{2} Q v_{O S}}{\omega_{r}}\right| \\
\left|v_{C_{P}}\right| & =\frac{\left|v_{O S}\right|}{n k \omega_{r}^{2}}\left|j n^{2} Q\left(\omega_{r}-\frac{1}{\omega_{r}}\right)+1\right|
\end{aligned}
$$

TABLE III

Design Specification of the Transcutaneous Converter

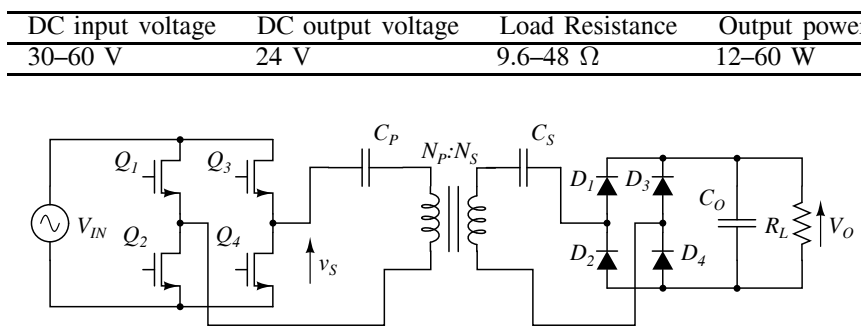

Fig. 2. Transcutaneous Converter.

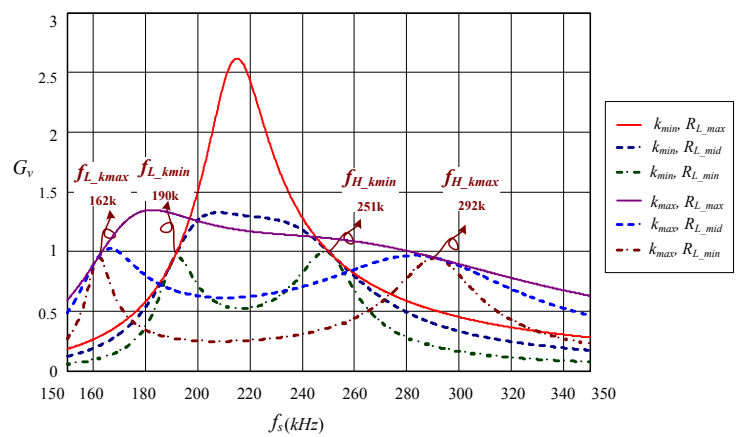

Fig. 3. Calculated frequency response of input-to-output voltage gain of the transcutaneous converter.

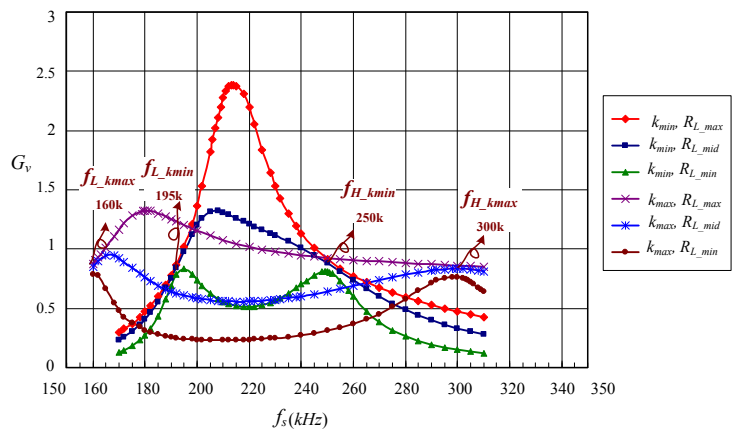

Fig. 4. Measured frequency response of input-to-output voltage gain of the transcutaneous converter.

Equations (25) and (26) are useful for determining capacitor voltage stress in deciding $Q$.

\section{Design and Control of Transcutaneous POWER CONVERTER}

A transcutaneous power converter shown in Fig. 2 has been built according to the specification shown in Table III. The components used are shown in Table IV. The calculated and measured frequency responses of input-to-output voltage gain without the control circuitry in Fig. 2 are shown in Figs. 3 and 4 respectively, indicating the lossless ideal model matches well with the experimental circuit. The frequencies $f_{H_{-} k m i n}$ and $f_{H_{-} k \max }$ in Figs. 3 and 4 are $\omega_{H} / 2 \pi$ in (10) for minimum and maximum $k$ 's respectively.

In previous design [17], frequencies well above the maximum of $\omega_{H}$ in (10) for all $k$ 's were used for frequency modulation in controlling the output voltage. Therefore, the design did not make use of the benefits, such as load 
TABLE IV

Power Components USED IN THE TRAnSCUtANEOUs CONVERTER

\begin{tabular}{|c|c|}
\hline Circuit component & value \\
\hline Power MOSFET $Q_{1}-Q_{4}$ & IRF540 \\
\hline Capacitance $C_{P}$ & $12.82 \mathrm{nF} / 200 \mathrm{~V}$ \\
\hline Capacitance $C_{S}$ & $14.57 \mathrm{nF} / 200 \mathrm{~V}$ \\
\hline Schottky Diode $D_{1}-D_{4}$ & MBR2535L \\
\hline Capacitance $C_{O}$ & $330 \mu \mathrm{F}$ \\
\hline Transcutaneous transformer & Ferrocube 3F3, PlanarEcore64/10/50 \\
\hline & $N_{P}=19$ turns of Litz wire AWG38\# $\times 32 \times 3$ \\
\hline & $N_{S}=17$ turns of Litz wire AWG38\# $\times 32 \times 3$ \\
\hline Switching frequency & $250-320 \mathrm{kHz}$ \\
\hline
\end{tabular}

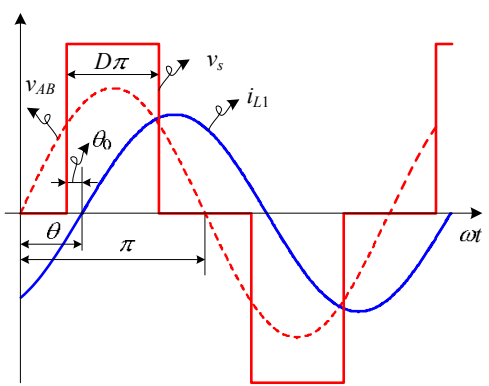

Fig. 5. Phase angle between the primary inductance current and the driving voltage when using the proposed PWM and PLL control.

insensitivity and small resonant tank circulation currents, in operating the converter near and just above $\omega_{H}$.

We use a control technique of pulse wide modulation and phase lock loop shown in Fig. 5 in achieving operation of the converter in a frequency above and close to $\omega_{H}$. The operation of the control circuit is briefly explained as follows. The switching frequency $f_{S}$ of the converter is clamped between $f_{S \min }\left(=f_{H_{-} \mathrm{kmin}}\right)$ and $f_{S \max }\left(=320 \mathrm{kHz}>f_{H_{-} \mathrm{kmax}}\right)$ shown in Fig. 4. A digital signal $i_{D}$ is produced using the zero crossing of the primary inductor current $i_{L_{1}}$ shown in Fig. 5. Phase difference of $i_{D}$ and $v_{S}$ is calculated and is locked to a fixed phase angle of $\theta_{0}$ by modulating the switching frequency of the converter. The angle $\theta_{0}$ is adjusted to be large enough for zero voltage switching of the full bridge switches. The operation frequency of the converter is therefore locked just above $\omega_{H}$ for full load while changing $k$. When there are changes for either a higher input voltage or lighter load, pulse width modulation will kick in, following Fig. 5, where the converter will operate at a frequency a bit higher than $\omega_{H}$ and phase angle $\theta$.

From Fig. 5, we have

$$
\begin{aligned}
\theta & =\theta_{0}+\frac{\pi(1-D)}{2}, \\
\left|v_{A B}\right| & =\frac{2 \sqrt{2}}{\pi} V_{\mathrm{IN}} \sin \frac{\pi D}{2} \\
\left|v_{O S}\right| & =\frac{2 \sqrt{2}}{\pi} V_{O}
\end{aligned}
$$

where $D$ is the duty cycle of the PWM control. The inputto-output voltage gain is modified to

$$
G_{d}(D)=G_{v}\left(2 \pi f_{\theta}\right) \sin \frac{\pi D}{2},
$$

where the phase lock loop circuitry will find a frequency $f_{\theta}$ satisfying (27) from which $G_{v}\left(2 \pi f_{\theta}\right)$ in (7) is obtained for calculating $G_{d}$ in (30). Fig. 6 shows the the relation between
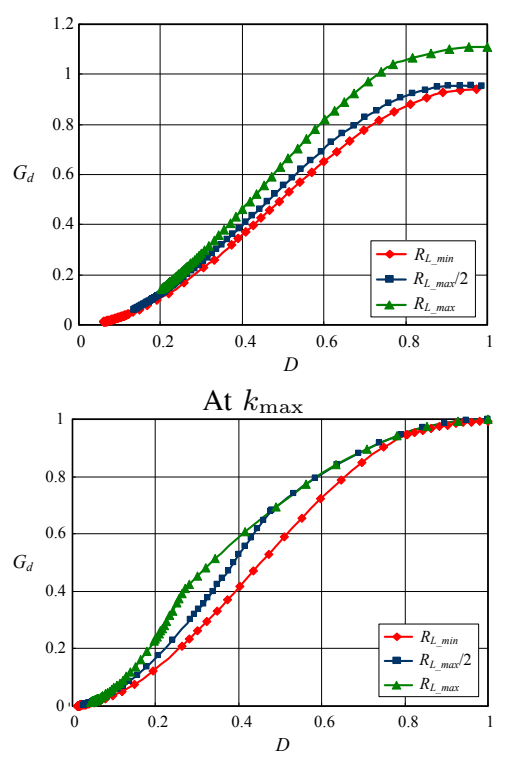

At $k_{\min }$

Fig. 6. Calculated duty cycle to input-to-output voltage gain transfer function for different loading conditions.

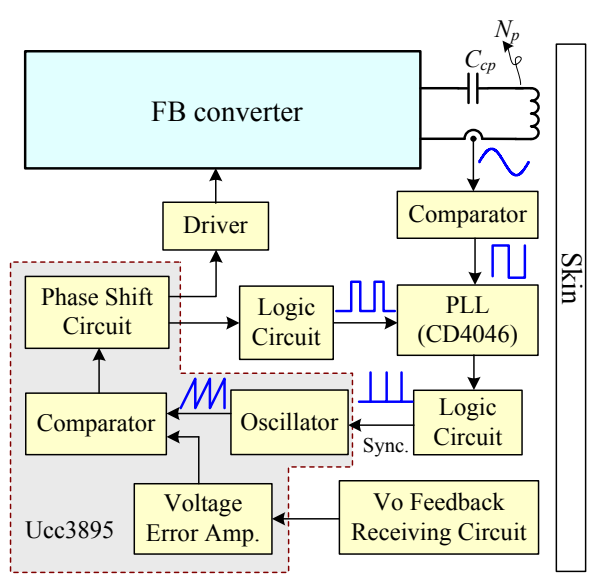

Fig. 7. Block diagram of control circuitry.

$D$ and $G_{d}$ for $k_{\max }$ and $k_{\min }$ at different loading conditions. Fig. 7 shows a block diagram of the control circuitry, implementing the PWM and PLL control of transcutaneous power converter. In the next section, we will evaluate the effectiveness of this control method.

\section{Evaluation of Transcutaneous Power CONVERTER}

A prototype shown in Fig. 8 of the proposed transcutaneous power regulator composed of converter in Fig. 2 and control circuit in Fig. 7 is built. Figs. 9, 10 and 11 give the transient responses of the transcutaneous power regulator undergone step changes in load, input voltage and coupling coefficient respectively. Fig. 12 gives the efficiency of the regulator at full load.

\section{CONCLUSION}

Transcutaneous power regulator for artificial heart has been studied in this paper. Compensation methods have been 


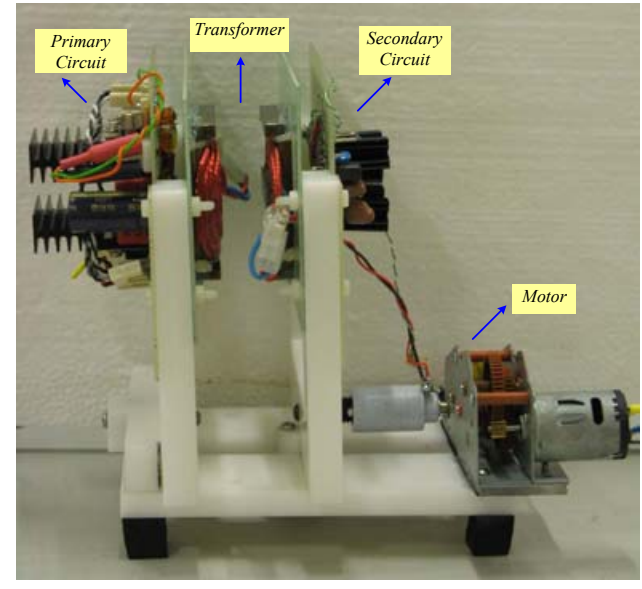

Fig. 8. Prototype transcutaneous power regulator.

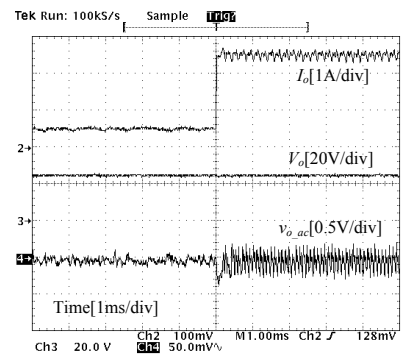

(a) from $\min$ to full load at $k_{\max }$

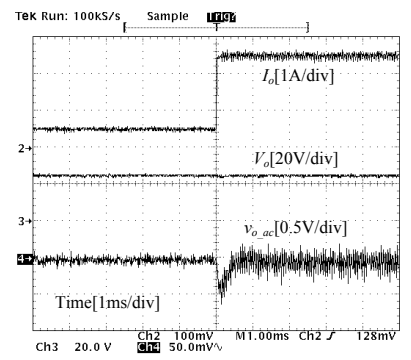

(c) from min to full load at $k_{\min }$

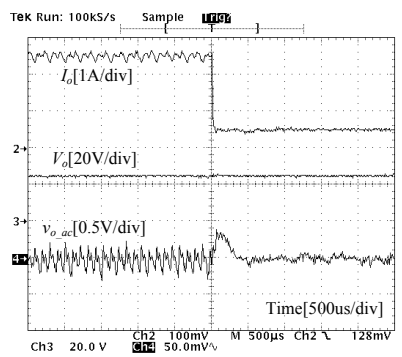

(b) from full to min load at $k_{\max }$

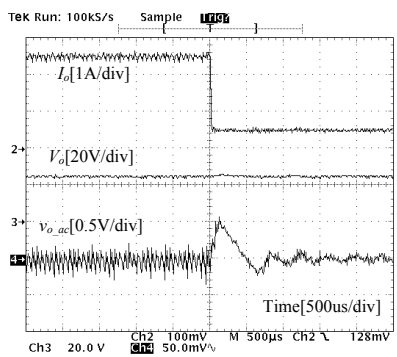

(d) from full to min load at $k_{\min }$

Fig. 9. Output voltage transient response of the transcutaneous regulator under a step change of load.

studied using fundamental frequency analysis on the input-tooutput voltage transfer function of a capacitor compensated transcutaneous transformer power converter. Based on the results of the analysis, new control method using both pulse width modulation and phase lock loop control has been proposed. The control method has been implemented in a transcutaneous power regulator. The power regulator has been evaluated for step changes in input voltages, output loads and transformer gaps as well as power conversion efficiency, giving excellent results.

\section{REFERENCES}

[1] W. H. Moore, D. P. Holschneider, T. K. Givrad and J. I. Maarek, "Transcutaneous RF-Powered Implantable Minipump Driven by a Class-E Transmitter," IEEE Trans. On Biomedical Engineering, vol. 53, No. 8, pp. 1705-1708, August 2006.

[2] G. Wang, W. Liu, M. Sivaprakasam and G. A. Kendir,"Design and Analysis of an Adaptive Transcutaneous Power Telemetry for Biomedical Implants," IEEE Trans. On Circuits and Systems - I: Regular Papers, vol. 52 pp. 2109-2117, October 2005.

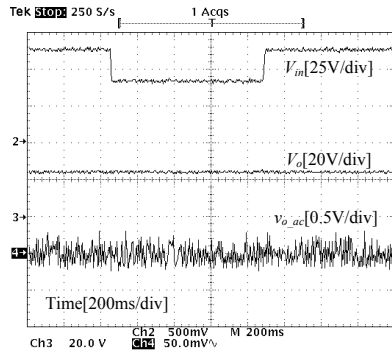

(a) $V_{\mathrm{IN}}=30-60 \mathrm{~V}$ at $k_{\max }$

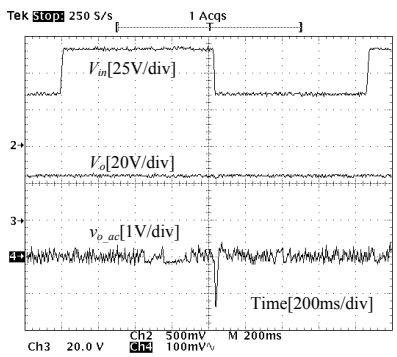

(c) $V_{\mathrm{IN}}=35-65 \mathrm{~V}$ at $k_{\max }$

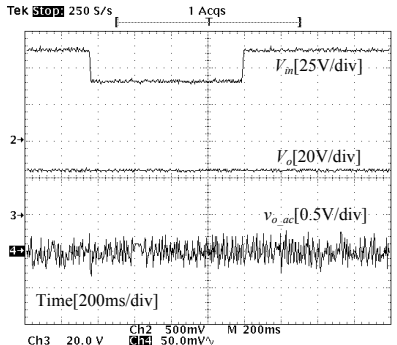

(b) $V_{\mathrm{IN}}=30-60 \mathrm{~V}$ at $k_{\mathrm{min}}$

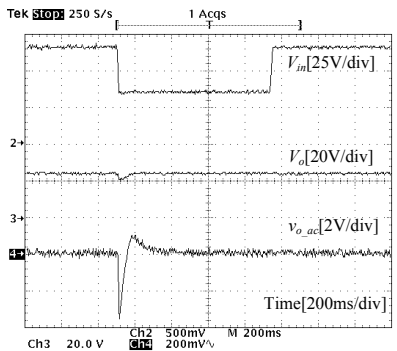

(d) $V_{\mathrm{IN}}=35-65 \mathrm{~V}$ at $k_{\mathrm{min}}$
Fig. 10. Output voltage transient response of the transcutaneous regulator at full load under a step change of input voltage $V_{\mathrm{IN}}$.

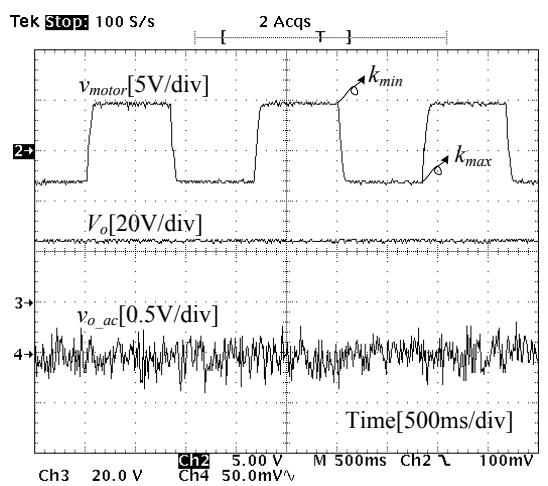

Fig. 11. Output voltage transient response of the transcutaneous regulator at full load under a change of transcutaneous transformer gap between $10 \mathrm{~mm}$ and $20 \mathrm{~mm}$, i.e. between $k_{\max }$ and $k_{\max }$.

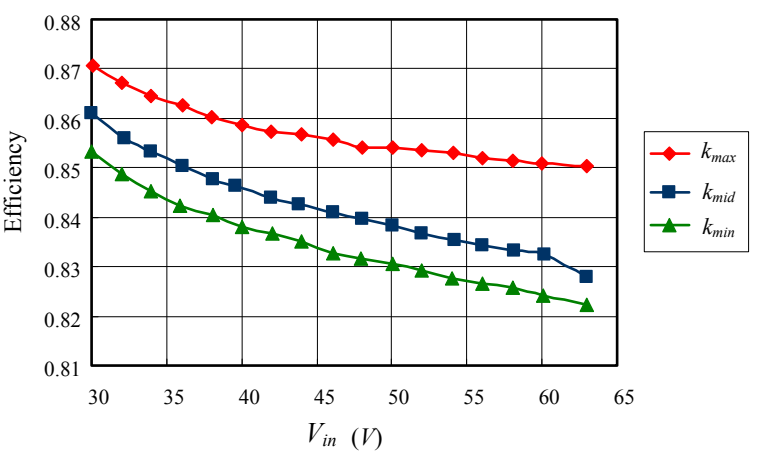

Fig. 12. Measured converter efficiency of the transcutaneous powe regulator at full load for different input voltages and coupling coefficients. 
[3] M. Watada, K. Iwawaki, T. Tamada, K. Ouchi, S. Takatani and Y. Um, "The development of Core-type Transcutaneous Energy Transmission System for Artificial Heart," Proc. IEEE Engineering in Medicine and Biology 27th Annual Conference, vol. 10, pp. 3849-3852, September 2005.

[4] H. G. Lim, Y. H. Yoon, C. W. Lee, I. Y. Park, B. S. Song and J. H. Cho, "Implementation of a Transcutaneous Charger for Fully Implantable Middle Ear Hearing Device," Proc. IEEE Engineering in Medicine and Biology 27th Annual Conference, vol. 10, pp. 6813-6816, September 2005.

[5] M. P. Theodoridis and S. V. Mollov, "Distant Energy Transfer for Artificial Human Implants," IEEE Trans. On Biomedical Engineering, vol. 52, no. 11, pp. 1931-1938, November 2005.

[6] N. M. Neihart, R. R. Harrison, "Micropower Circuits for Bidirectional Wireless Telemetry in Neural Recording Application," IEEE Trans. On Biomedical Engineering, vol. 52, no. 11, pp. 1950-1958, November 2005.

[7] T. Takura, H. Ishiai, F. Sato, H. Matsuki, and T. Sato, "Basic Evaluation of Signal Transmission Coil in Transcutaneous Magnetic Telemetry System for Articial Hearts," IEEE Trans. On Magnetics, vol. 41, no. 10, pp. 4173-4175, October 2005.

[8] N. Chaimanonart, K. R. Olszens, M. D. Zimmerman, W. H. Ko, and D. J. Young, "Implantable RF Power Converter for Small Animal In Vivo Biological Monitoring," Proc. IEEE Engineering in Medicine and Biology 27thAnnual Conf., pp. 5194-5197, September 2005.

[9] W. Ying, Y. Luguang, and X. Shangang, "Modeling and Performance Analysis of a New Contactless Power Supply System," Proceedings of the Eighth International Conference on Electrical Machines and Systems, ICEMS 2005, pp. 1983 - 1986, September 2005.

[10] K. S. Guillory, A. K. Misener and A. Pungor, "Hybrid RF/IR Transcutaneous Telemetry for Power and High-Bandwidth Data," Proc. Of the 26th Annual International Conf. of IEEE EMBS, pp. 4338-4340, 2004.

[11] K. Iwawaki, M. Watada, S. Takatani and Y. Um, "The Design of Core-type Transcutaneous Energy Transmission Systems for Artificial Heart," The 30th Annual Conference of the IEEE Industrial Electronics Society, pp. 948 - 952, Nov. 2004.

[12] A. Homma, Y. Taenaka, E. Tatsumi, Y. Takewa, T. Kamimura, H. Naitoh, M. Oshikawa, T. Mizuno, K. Shioya, H. S. Lee, T. Tsukiya, Y. Kakuta, N. Katahiri, H. Takano, S. Kitamura, K. Koshiji, K. Shiba, Y. Fukui, H. Wakui, K. Tsuchimoto, H. Fukuda and K. Tsukahara, "Current Status of National Cardiovascular Center Totally Implantable
Artificial Heart System," SICE Annual Conference in Sapporo, pp. 436 - 440, August 2004.

[13] S. Shabou, N. Rekik, M. Ghorbel, A. B. Hamida and M. Samet, "Conception of an Emitter for Transcutaneous Power and High-speed Data Transmission," 2004. Proc. The 16th International Conference on Microelectronics, pp. 655 - 659, 2004.

[14] H. Oman, "Articial Hearts, Batteries, and Electric Vehicles," IEEE AESS Systems Magazine, pp. 34 - 39, August 2002.

[15] T. H. Nishimura, T. Eguchi, A. Kubota, K. Hamamoto and M. Saito, "An Improved Transmission Energy Transformer for a Non Invasive Rechargeable Battery to Artificial Organs," The 8th IEEE International Conference on Electronics, Circuits and Systems, ICECS, pp. 1209 $1214,2001$.

[16] L. Zhao, C. F. Foo and K. J. Tseng, "A New Structure Transcutaneous Transformer for Artificial Heart System," IEEE Trans. On Magnetics, vol. 35, no. 5, pp. 3550 - 3552, November 1999.

[17] G. B. Joung and B. H. Cho, "An Energy Transmission System for an Artificial Heart Using Leakage Inductance Compensation of Transcutaneous Transformer," IEEE Transactions on Power Electronics, vol. 13, no. 6, pp. 1013 - 1022, November 1998.

[18] K. Shiba, E. Shu, K. Koshiji, K. Tsukahara, K. Tsuchimoto, T. Ohu-mi, T. Nakamura, S. Endo, T. Masuzawa, E. Tatsumi, and Y. Taenaka, "Efficiency Improvement and in Vivo Estimation of Externally-Coupled Transcutaneous Energy Transmission System for a Totally Implantable Artificial Heart," Proc. IEEE/EMBS, pp. 2503 - 2505, Oct. 1997.

[19] H. Matsuki, Y. Yamakata and N. Chubachi, "Transcutaneous DC-DC Converter for Totally Implantable Artificial Heart Using Synchronous Rectifier," IEEE Trans. On Magnetics, vol. 32, no. 5, pp. 5118 - 5120, September 1996.

[20] C. G. Kim and B. H. Cho, "Transcutaneous Energy Transmission with Double Tuned Duty Cycle Control," Proceedings of the 31st Intersociety Energy Conversion Engineering Conference IECEC 96, pp. 587 - 591, 1996.

[21] A. Ghahary and B. H. Cho, "Design of a Transcutaneous Energy Transmission System Using a Series Resonant Converter" IEEE Trans. On Power Electronics, vol. 7, no. 2, pp. 261 - 269, April 1992.

[22] H. Matsuki and M. Shiki, "Investigation of Coil Geometry for Transcutaneous Energy Transmission for Artificial Heart," IEEE Trans. On Magnetics, vol. 28, no. 5, pp. 2406 - 2408, September 1992.

[23] M. W. Baker and R. Sarpeshkar, "Feedback Analysis and Design of RF Power Links for Low-Power Bionic System," IEEE Trans. On Biomedical Circuit and Systems, vol. 1, no. 1, pp. 28 - 38, March 2007. 